\title{
Electromagnetic Field Interference on Transmission Lines due to On-Board Antenna
}

\author{
Heekwon Lee, ${ }^{1,2}$ Soojung Ryu, ${ }^{2}$ Seungbae Lee, ${ }^{3}$ SoYoung Kim, ${ }^{2}$ and Wansoo $\mathrm{Nah}^{2}$ \\ ${ }^{1}$ Department of Product Development, Samsung Display, Asan, Chungcheongnam-do 336-741, Republic of Korea \\ ${ }^{2}$ College of Information and Communication Engineering, Sungkyunkwan University, Suwon, Gyeonggi-do 440-746, Republic of Korea \\ ${ }^{3}$ Technology Quality \& Reliability Group, Samsung Electronics, Suwon, Gyeonggi-do 443-742, Republic of Korea
}

Correspondence should be addressed to Wansoo Nah; wsnah@skku.edu

Received 25 January 2015; Revised 24 April 2015; Accepted 30 April 2015

Academic Editor: Xiaoxiong (Kevin) Gu

Copyright (c) 2015 Heekwon Lee et al. This is an open access article distributed under the Creative Commons Attribution License, which permits unrestricted use, distribution, and reproduction in any medium, provided the original work is properly cited.

\begin{abstract}
As the available space in the board of a mobile device becomes smaller and more compact, circuit elements and transmission lines are arranged in very close proximity, especially from the antennas which are usually installed on the same board. Due to the various on-board antennas which are designed in small space, the transmission lines on the board are electromagnetically interfered, resulting in the performance degradation of the circuit. So the engineers and circuit designers should find the least interfered place for the transmission lines and components to minimize the electromagnetic interferences. This paper discusses and presents a methodology to find the least sensitive position in the induced current distribution as well as in the noise power delivered from the antenna. For this purpose some vertical, horizontal, and bent transmission lines with antenna on the same board are designed and fabricated with and without common ground, and the transferred powers to the transmission lines were measured and were also simulated using a full-wave simulator. The results predicted by the EM simulation model were successfully confirmed through the measurement of $S$-parameters in the experimental setup, which shows the validness of the suggested analysis method.
\end{abstract}

\section{Introduction}

Recent development in mobile devices aims to slim down the design for cellular phones and pads. The integration of various other modules within one slim structure makes it difficult to avoid mutual electromagnetic interference inside, especially from the on-board antennas. Quite often this circumstance results in the signal and power deformation or distortion, degrading the whole performance of the device [1].

Antenna is, of course, designed for maximum radiation at the resonance frequency in any case [2], and one way to reduce the coupling noise could be to suppress the antenna radiation power itself, but this is absolutely against the design target of the antenna and will degrade the whole performance of the device. So the overall system design should be such that the power should be maximally radiated at the resonance frequency while still minimizing the transferred power to the near circuit elements on the PCB from the antennas. This indicates that the placement of all the other modules (e.g., display, battery, etc.) on the board should also be taken into consideration at the very design stage [3], because the amount of the noise power delivered from the antenna may vary depending on the location of the elements and the transmission lines connecting them [4-7]. Of the various elements on the board, the transmission lines connecting the elements should be the longest or largest elements on the board [8], which suggests that the electromagnetic interference could be occurring most significantly at the transmission lines.

In [4], the authors studied the effects of the transferred noise from the on-board antenna to the embedded transmission lines on the integrated board. In this paper, we present a methodology to find the least sensitive positions to receive noise power from antennas with and without common ground. For this purpose some vertical, horizontal, and bent transmission lines were designed and fabricated to measure the transferred power from the PIFA (planer inverted $\mathrm{F}$ antennas) antenna. Basically, the transferred noise power to the transmission line is also dependent on the terminal loads, which makes the situation complicated, but in this paper we used the insertion losses to represent 


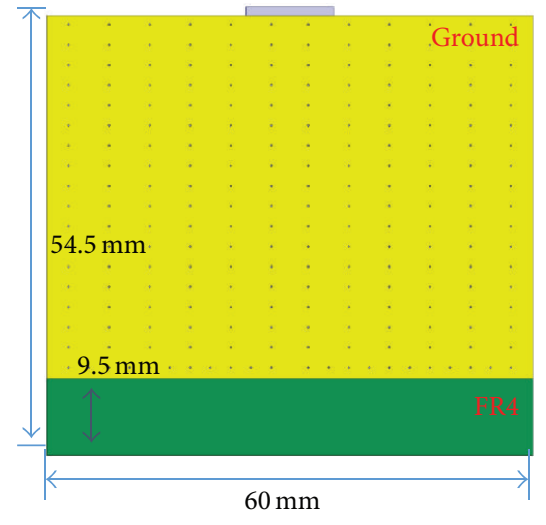

(a)

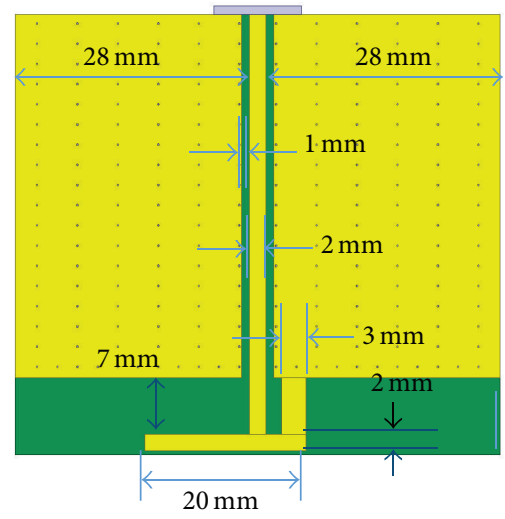

(b)

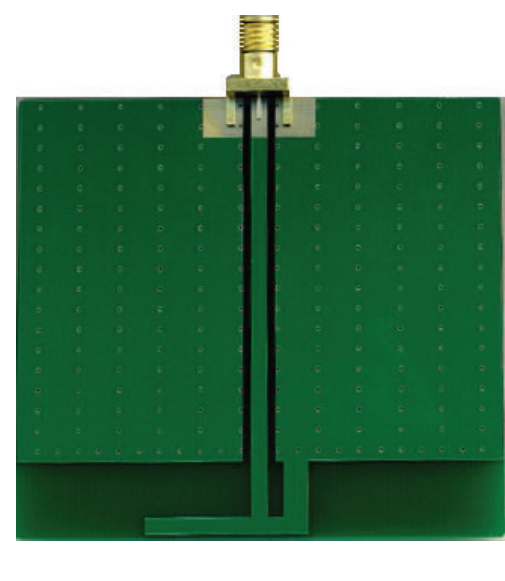

(c)

FIgURE 1: Configuration of the PIFA antenna: (a) bottom view, (b) top view, and (c) photograph of the PIFA antenna.

the transferred power to the transmission lines, of which validity is described in Section 3. The transferred noise powers were also simulated by full-wave EM simulator, and the results showed quite a good agreement with the measured insertion losses.

In Section 2, an evaluation board with a PIFA antenna and the microstrip transmission lines are described. The proposed PIFA antenna and transmission lines are good simplified versions of the real complicated mobile circuits to show the couplings between them. Section 3 describes the formulas for the transferred power and proposes an effective index to evaluate the transferred power from antenna to the transmission lines. In Section 4, comparisons of current distribution on the board and the delivered noise power to the transmission lines are elaborated with separate or common ground plane with antenna. The results show that transmitted power is strongly dependent on the relative position of transmission line from the edges of the board instead of the distance from the antenna. In Section 5 the transferred powers to transmission lines in far and near fields are described. It is proved that due to the localized near field, the power transfer to the transmission line is not sharp around the resonance frequency of the antenna.

Section 6 compares the magnitude of power delivered from antenna to the multiple transmission lines. Three kinds of the transmission lines (microstrip, strip line, and CPW) are implemented on the boards, and the experiments were performed to compare the magnitude of the transferred power to the transmission lines. In the end of Section 6, a design guide to reduce the electromagnetic field interference on transmission lines due to on-board antenna is described. Finally the conclusions are made in Section 7.

\section{Antenna and Microstrip Transmission Lines on the Board}

2.1. Antenna. The PIFA antenna which was used in the experiment and in the EM simulation is shown in Figure 1. It

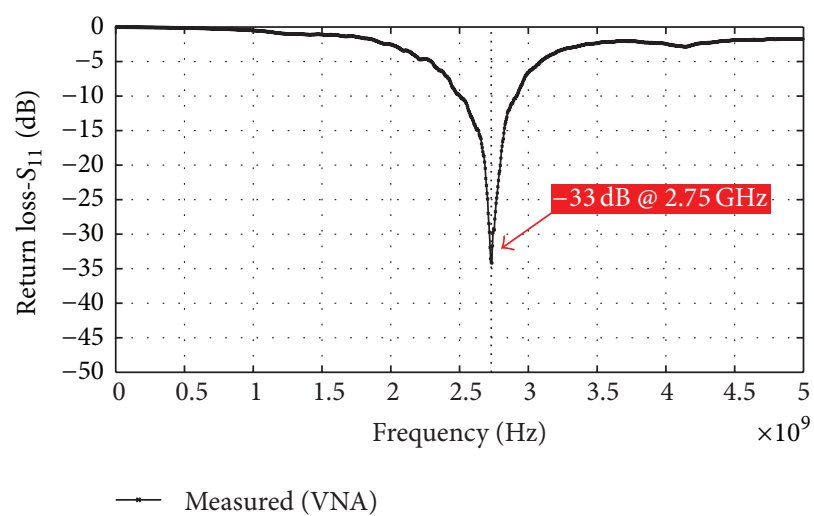

Figure 2: Measured return loss of the PIFA antenna.

was fabricated on the FR4 $\left(\varepsilon_{r}=4.6\right)$ substrate with a $1.6 \mathrm{~mm}$ thickness, and the copper on the substrate is $0.035 \mathrm{~mm}$ thick. The area of antenna is of $60 \times 9.5 \mathrm{~mm}^{2}$ and the antenna is fed through CPW (coplanar waveguide) with ground as described in Figure 1. The PIFA antenna was designed to have a single band at $2.75 \mathrm{GHz}$, and Figure 2 shows the return loss characteristics of the antenna.

2.2. Transmission Lines on the Board. Simplified microstrip transmission lines were installed on the board, inspired by $[4,5]$, to emulate the transmission lines in the actual mobile device. They are located at five positions (Upper 1, Upper 2, Middle, Lower 1, and Lower 2) and of three configurations (vertical, horizontal, and bent) as described in (a) and (b) of Figure 3, respectively. The Upper lines are near the antenna, of course, and the Lower lines are far from it. The physical distances between the antenna and the transmission lines were summarized to be Upper $1 \leqq$ Upper $2<$ Middle $<$ Lower $1 \leqq$ Lower 2. Notice also Upper and Lower lines are near at least one edge of the board, and the Middle line is far from the four edges of the board. The length of the vertical and bent transmission lines is $50 \mathrm{~mm}$, and that of the horizontal 


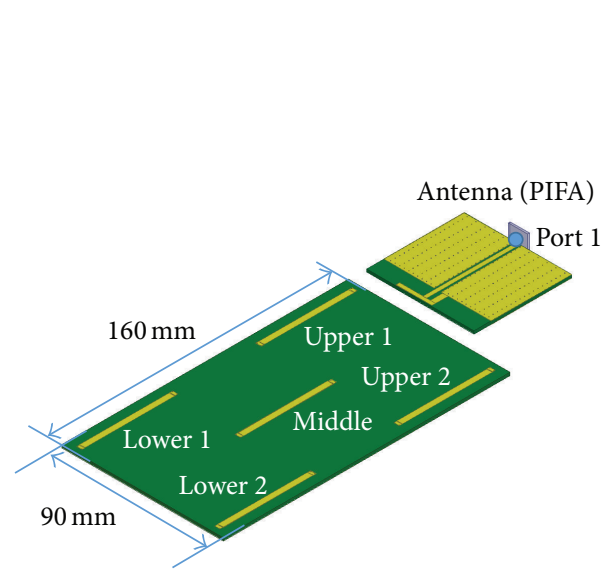

(a)
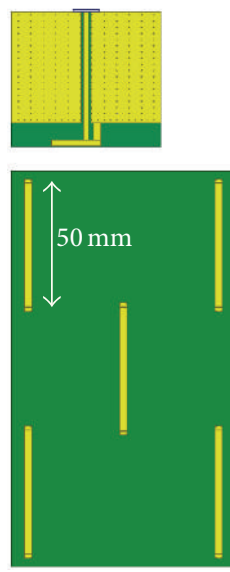
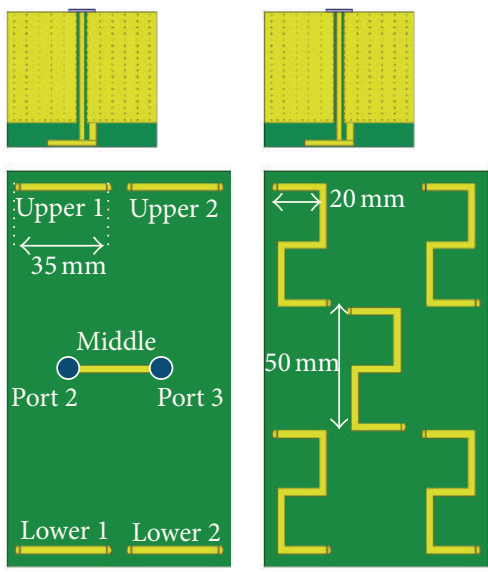

(b)

Figure 3: Antenna and transmission lines on the board. (a) Five positions of transmission lines and (b) three configurations of transmission lines on the board: vertical, horizontal, and bent. Port 1 is at the feeding port of the antenna and Port 2 and Port 3 are at the two ends of transmission lines.

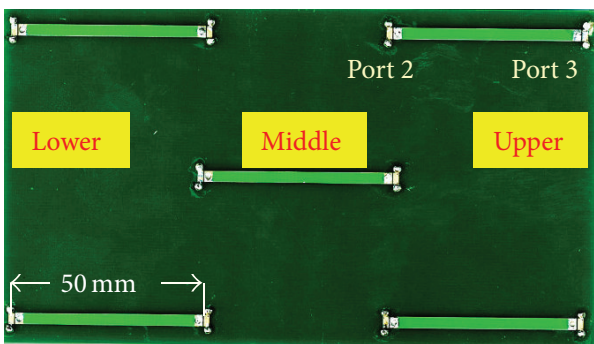

(a)

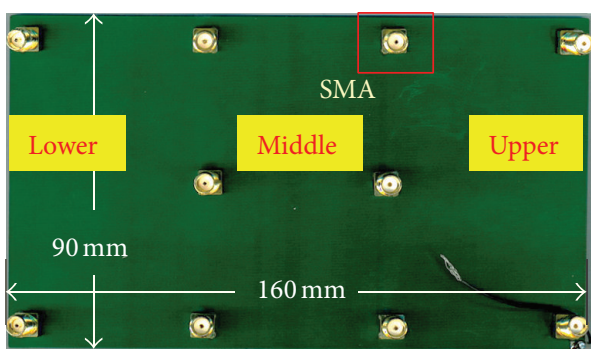

(b)

FIGURE 4: Photographs of the microstrip transmission lines on the board: (a) top view, (b) bottom view.

transmission line is $35 \mathrm{~mm}$. All the transmission lines are designed to have $50 \mathrm{Ohm}$ of characteristic impedance. At the two end terminals of each microstrip transmission line, SMA connectors were installed on the bottom side of the board through vias as in Figure 4, and they are connected to the vector network analyzer (VNA). Port 1 is assigned to the antenna feeding port, and Port 2 and Port 3 are at the two ends of transmission lines as described in Figures 3 and 4.

\section{Transferred Power to Transmission Line from Antenna}

3.1. Dependence on Source and Load Impedances. The transferred power from the source to the load is, of course, dependent on the source and load impedances. Figure 5(a) shows a simplified diagram of an antenna and transmission line circuits on the board. Antenna is fed from Port 1 and impedances are installed at Ports 2 and 3 at two ends of the transmission line. Three by three $S$-parameters of this circuit can be extracted by a 3D EM simulator, and the transferred power from Port 1 to Ports 2 and 3 can also be calculated using a circuit simulator. Figure 5(b) is a simplified equivalent circuit of the right side of (a). Power at each port can be expressed as in the following:

$$
\begin{aligned}
P_{\text {supply }} & =P_{s}+P_{\text {in }} \\
& =\operatorname{Re}\left(\frac{1}{2} Z_{s} \cdot I^{2}\right)+\frac{\left|V_{s}\right|^{2}}{8 Z_{0}} \frac{\left|1-\Gamma_{s}\right|^{2}}{\left|1-\Gamma_{s} \Gamma_{\text {in }}\right|^{2}}\left(1-\left|\Gamma_{\text {in }}\right|^{2}\right) \\
\Gamma_{s} & =\frac{Z_{s}-Z_{0}}{Z_{s}+Z_{0}}, \\
\Gamma_{\text {in }} & =\frac{Z_{\text {in }}-Z_{0}}{Z_{\text {in }}+Z_{0}},
\end{aligned}
$$

where $V_{s}$ is source voltage, $Z_{s}$ is source impedance, $Z_{\text {in }}$ is input impedance of an antenna, $Z_{0}$ is characteristic impedance of the transmission line, $\Gamma_{s}$ is reflection coefficient 


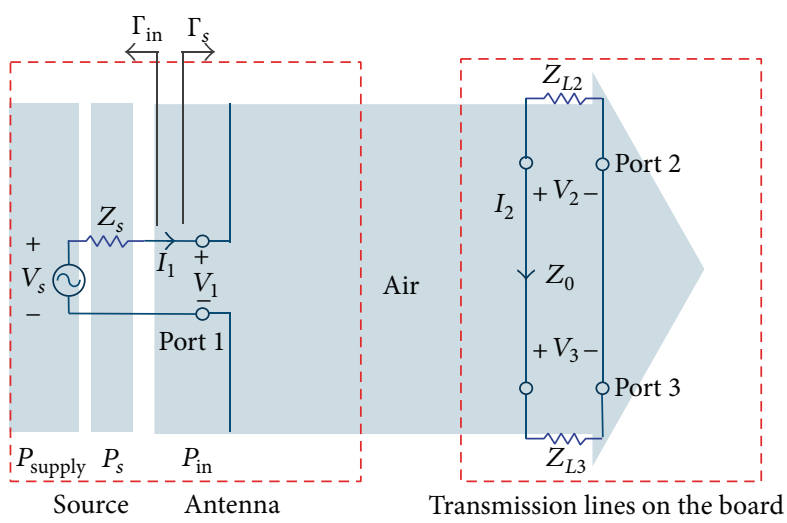

(a)

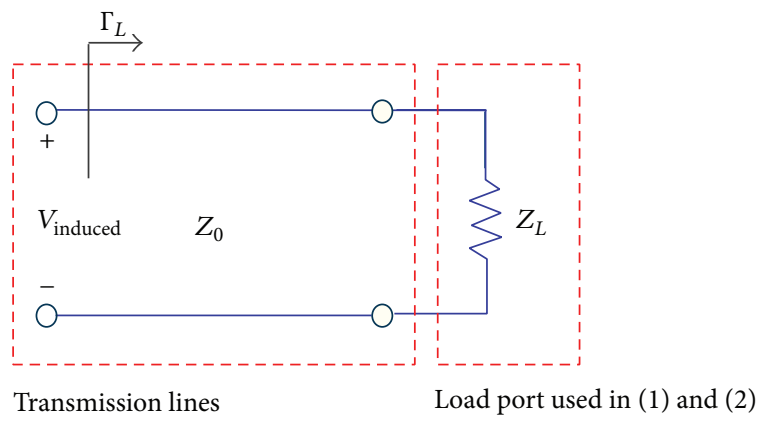

(b)

FIGURE 5: (a) Diagram for an antenna and transmission lines on the board. (b) Simplified equivalent transmission line model of the right side of (a). Note that $Z_{L}$ is an equivalent impedance for the sum of $Z_{L 2}$ and $Z_{L 3}$.

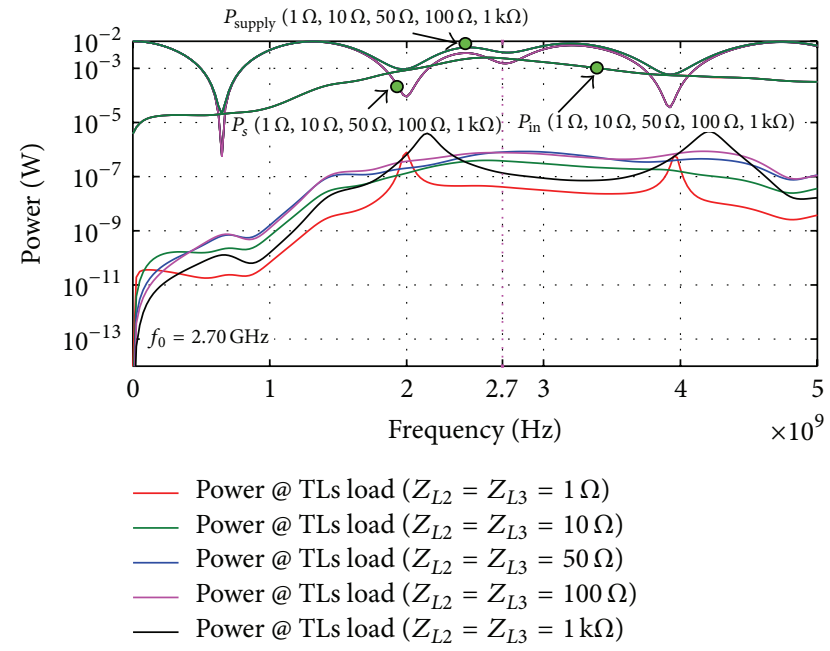

FIGURE 6: Simulated variation of powers due to the change of loads when $Z s$ is $50 \Omega$.

toward the source at the input port, and $\Gamma_{\text {in }}$ is reflection coefficient toward the antenna at the input port:

$$
\begin{gathered}
P_{L}=\frac{\left|V_{s}\right|^{2}}{8 Z_{0}} \frac{\left|1-\Gamma_{s}\right|^{2}}{\left|1-\Gamma_{s} \Gamma_{\text {in }}\right|^{2}} \frac{\left|S_{21}\right|^{2}\left(1-\left|\Gamma_{L}\right|^{2}\right)}{\left|1-S_{22} \Gamma_{L}\right|^{2}} \\
\Gamma_{L}=\frac{Z_{L}-Z_{0}}{Z_{L}+Z_{0}}
\end{gathered}
$$

where $\Gamma_{L}$ is reflection coefficient at the load and $Z_{L}$ is load impedance of transmission line.

In the two equations, $P_{\text {supply }}$ is the power supplied by the source, and $P_{s}$ is the power consumption due to the internal source impedance $Z_{s}$. $P_{\text {in }}$ and $P_{L}$ are the powers delivered to the antenna input port and the load, respectively. These four powers $P_{\text {supply }}, P_{s}, P_{\text {in }}$, and $P_{L}$ are shown in Figure 6 for the circuit of Upper 1, horizontal transmission line in Figure 3, which is the closest to the antenna. One can see that the $P_{L}$ is about $10^{-4} \sim 10^{-5}$ times smaller compared to $P_{\text {in }}$, which is the input power to the antenna. This is because most of the input power is radiated out into the air, and only a small part of it is delivered to the transmission lines on the board. Also the variation of $P_{L}$ is not much large even when the load changes quite a lot from $1 \Omega$ to $1 \mathrm{k} \Omega$. Furthermore, noting that $P_{\text {supply }}$ and $P_{\text {in }}$ do not almost change with the wide load variations, it could be plausible to fix the load impedance to be of $50 \Omega$ for the analysis of the transferred power to the transmission lines for the general load conditions.

3.2. Power Transfer Index. To make a quantitative analysis of the transferred power to the transmission line, one needs to define the transferred power index $\left(G_{\text {index }}\right)$ from antenna to transmission lines. One of the candidates could be the ratio of the input power to the output power, defined as $P_{L} / P_{\text {in }}$, as described in

$$
G_{\text {index }}=\frac{P_{L}}{P_{\text {in }}}=\frac{\left|S_{21}\right|^{2}\left(1-\left|\Gamma_{L}\right|^{2}\right)}{\left(1-\left|\Gamma_{\text {in }}\right|\right)^{2}\left|1-S_{22} \Gamma_{L}\right|^{2}} .
$$

Since there is little change in $P_{\text {in }}$ with load impedance variations, so is $\Gamma_{\text {in }}$, and $\Gamma_{\text {in }}$ can be regarded as a constant in (3). Because we are interested in the relative transferred power, it is reasonable to take $\Gamma_{\text {in }}$ to be of zero, without loss of generality. Finally, if we take the load impedance to be of $50 \Omega$ as suggested in the previous section, $G_{\text {index }}$ is simplified to be

$$
G_{\text {index }}=\left|S_{21}\right|^{2} \text {. }
$$

Finally, adding Port 3 in (a) of Figure 5, power transfer index can be defined as (5), and this index will be used to represent the transferred power to the transmission lines from antenna in this paper [9]

$$
G_{\text {index }}=\left|S_{21}\right|^{2}+\left|S_{31}\right|^{2} .
$$




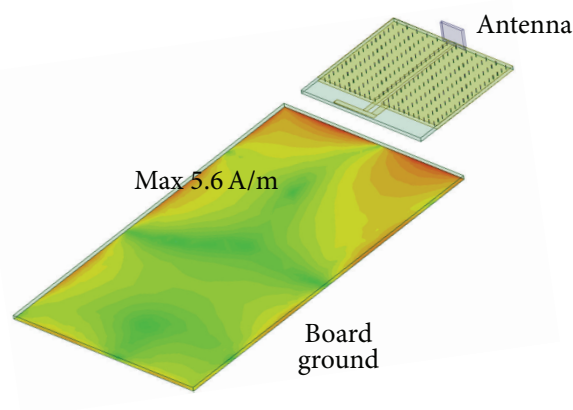

(a)

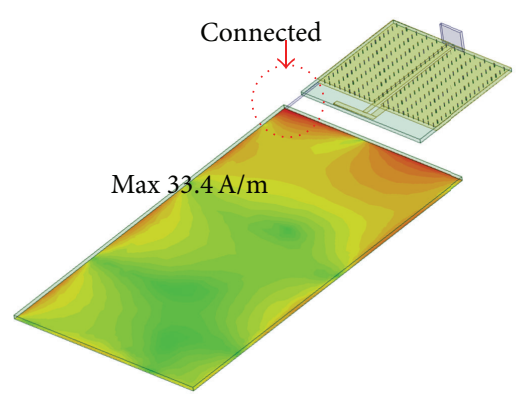

(c)

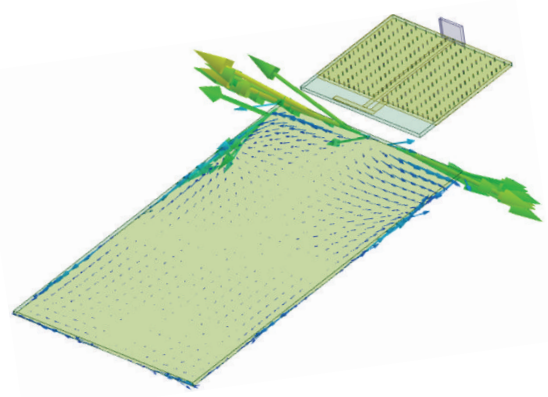

(b)
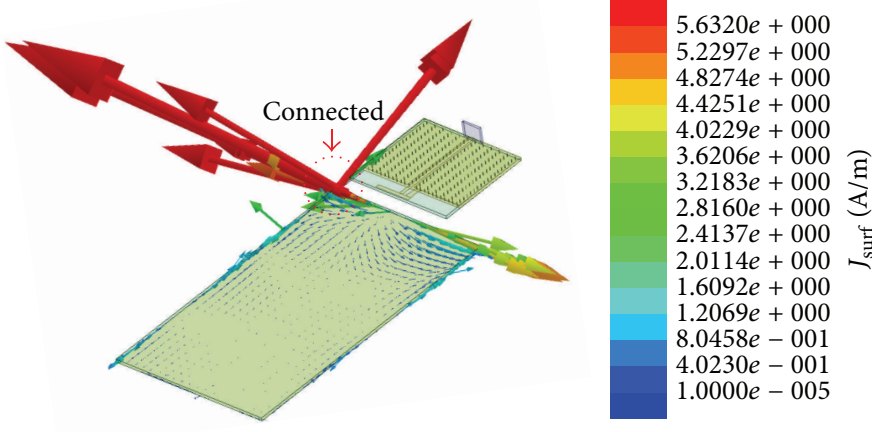

(d)

FIGURE 7: Induced current distribution on the ground plane without transmission lines (a) with separate ground (b) current vectors with separate ground (c) with common ground (d) current vectors with common ground.

\section{Induced Current Distribution and Transferred Power to the Transmission Lines in Different Location}

4.1. Induced Current Distribution on the Ground Plane. Figures 7 (a) and 7 (b) show the induced current distribution and the current vectors in the board ground at resonance frequency when the board ground is not connected to the antenna ground. On the other hand, (c) and (d) are when the board ground is connected to the antenna ground at the upper/left side of the board. As can be seen from the figures, the currents are concentrated at the edges of the board [10], especially at the top side of the board, which is the closest to the antenna. This is the same phenomenon found in a previous study [11]. When the antenna ground is connected to the board ground, the maximum current density increases about six times higher than the current density with no ground connection. However, there is basically no significant change in the current distribution for both cases as a whole.

Due to the interactions between antenna and board, the antenna characteristics could change. Figure 8 shows measured return loss characteristic of the antenna with and without the board around antenna. Resonance frequency of the stand-alone antenna is $2.75 \mathrm{GHz}$ as described in Figure 2,

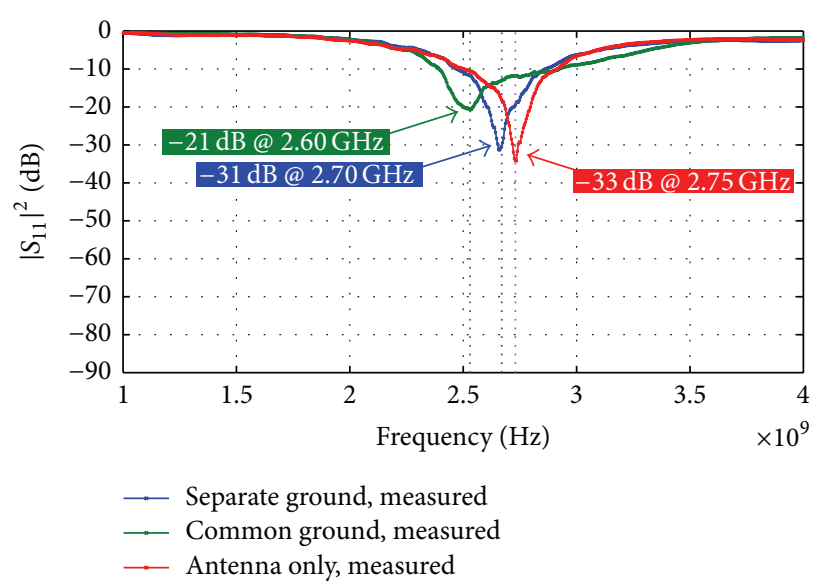

Figure 8: Power of the antenna with and without board around.

and it is repeated in Figure 8 for the comparison of the antenna with boards. It is good to see that the resonance frequency is shifted to $2.70 \mathrm{GHz}$ and $2.60 \mathrm{GHz}$ for the separate ground and common ground, respectively. This could be due to the introduction of capacitance around the antenna, and the more the current is induced, the more interactive the 


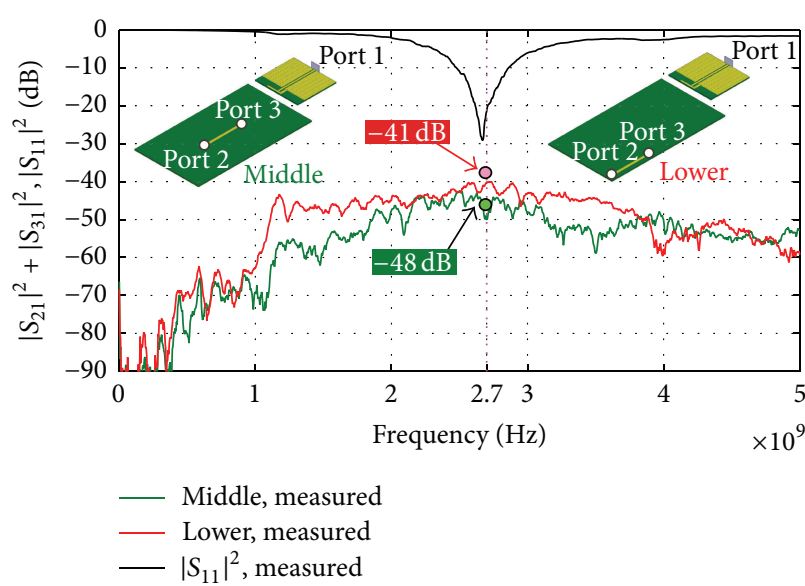

(a)

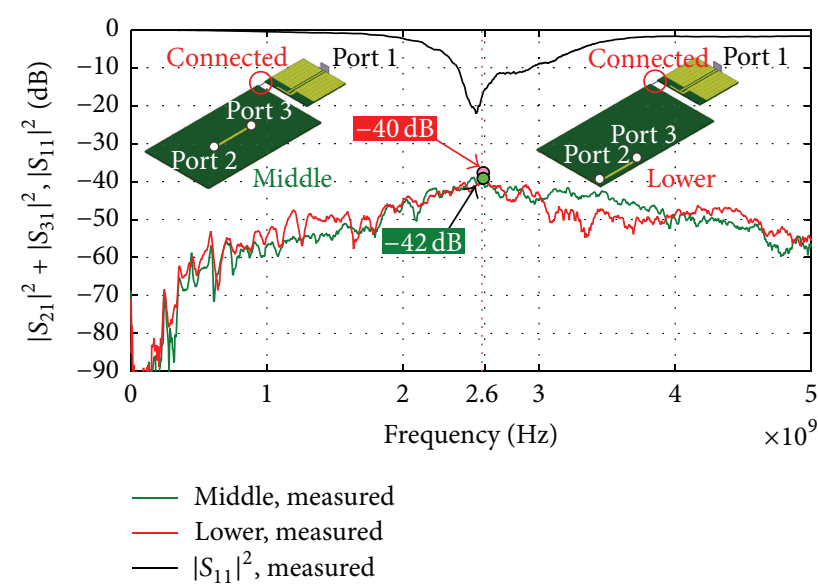

(b)

FIGURE 9: (a) Measured power from antenna to the single transmission line with separate ground (@2.70 GHz), (b) measured power from antenna to single transmission line with common ground (@2.60 GHz).

capacitance could be. This suggests that the results from the EM simulation are consistent with the measured data, at least qualitatively.

\subsection{Position Effects of Single Transmission Line on the Board.} From the current distribution of the board ground in Figure 7, the next step could be to check if the transferred power to the transmission line on the board becomes larger at the edges of the board or not. Small pictures in Figure 9 are the evaluation models to demonstrate the physical location of a single transmission lines on board. The $G_{\text {index }}$ defined in (5) was measured for each single transmission line, and the return loss of the antenna is also repeated in each graph to check the resonance frequency of the antenna. As predicted from the current distribution, the transferred power is larger $(2 \sim 7 \mathrm{~dB})$ in the transmission lines near the edge of the board than in the Middle transmission line. Noting that Lower transmission line is farther from the antenna than the Middle transmission line, it means that the transferred power is strongly dependent on the relative position of transmission lines from the edges of the board instead of the physical distance from antenna. The results also show that the delivered power increases with ground connection about $1 \mathrm{~dB} \sim 6 \mathrm{~dB}$ at resonance frequency.

\section{Transferred Power to a Transmission Line in Near and Far Fields}

It is quite satisfactory to see that the transferred power from antenna to the transmission line in Figure 9 has its maximum value at the resonance frequency of the antenna, but the transferred power around the resonance frequency does not decrease sharply as might be expected from $\left|S_{11}\right|^{2}$ configuration in the same figure. Noting that the electromagnetic field in the board from the antenna could be in the near field region, the magnitude of the electric field away from antenna was electromagnetically simulated. Figure 10(e) depicts the electric field without any board along the path, and (b) (d) are for the electric field along the edge line of the board, and (f) (h) are for the electric field along the center line of the board as described in (a). The distance from antenna to the board is at $10 \mathrm{~mm}$ (near field), $5 \lambda(0.55 \mathrm{~m}$, near field), and $10 \lambda(1.1 \mathrm{~m}$, far field) at the resonance frequency of $2.70 \mathrm{GHz}$. Notice also that all the boards in Figures 3, 7, and 11 are $10 \mathrm{~mm}$ away from the antenna. Along the center line of the board, the electric fields disappear at the board location as in Figures 10(f)-10(h), which can be predicted from the current distribution on the board. Along the edge of the board, however, high electric fields appear at the board location, which can also be expected from the current distribution on the board. It is interesting to see that the high electric fields at various frequencies are induced in the near field location at $10 \mathrm{~mm}$ and $0.55 \mathrm{~m}$ as in Figures 10(b)-10(c), while high electric field is induced at only resonance frequency in the far field location as in Figure 10(d). It is well known that the electromagnetic fields in the near field are quite localized, while the fields are radiated away efficiently at resonance frequency of the antenna in the far field region. Since the board in a mobile device is quite near the antenna, it is in the near field region, so the electromagnetic fields can be induced in a wide frequency range around the resonance frequency as in Figures 10(b)-10(c). These results agree quite well with the measured transferred power as described in Figures 9 and 12.

\section{Transferred Power to Multiple Transmission Lines in Near Field}

From the analysis so far, it is clear that the induced current distribution on board plays quite a role in the analysis of power transfer to the transmission lines from the antenna. Figure 11 shows the induced current distribution on the board again but in this case for the five vertical microstrip transmission lines. From the figure, with even multiple transmission lines on the board, we see high current density at 


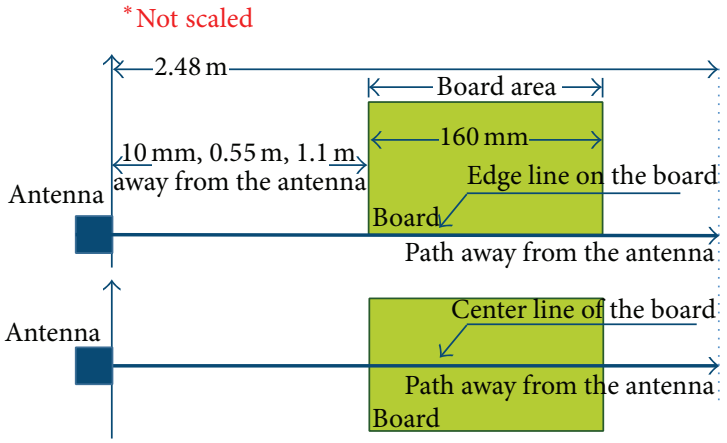

(a)

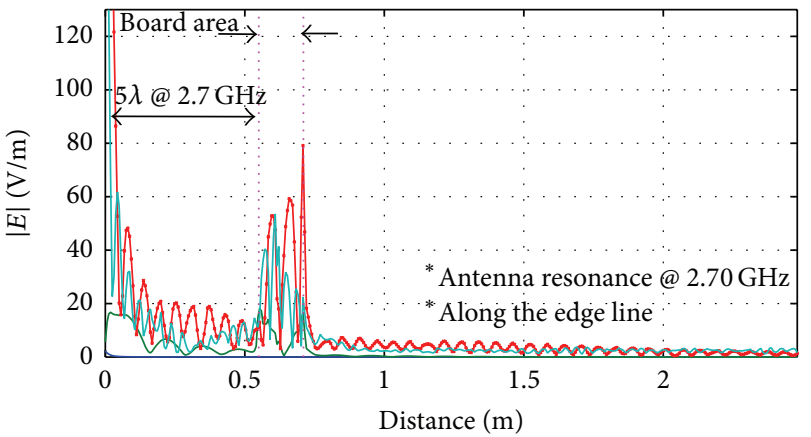

(c)

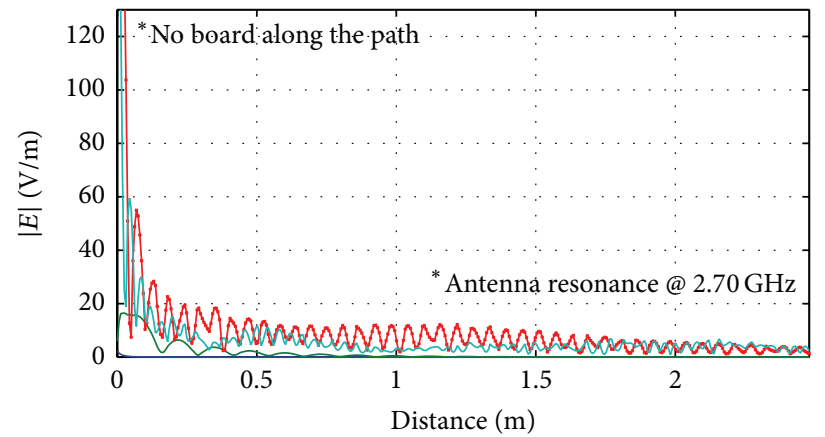

(e)
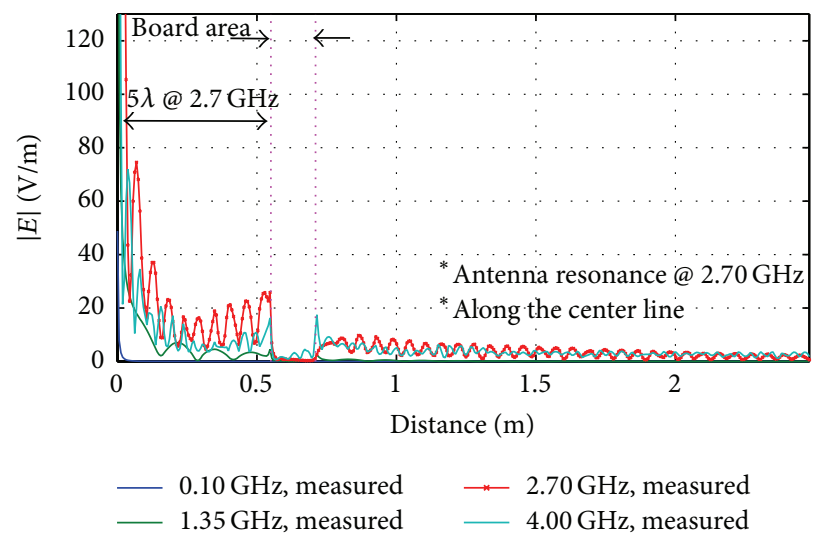

(g)

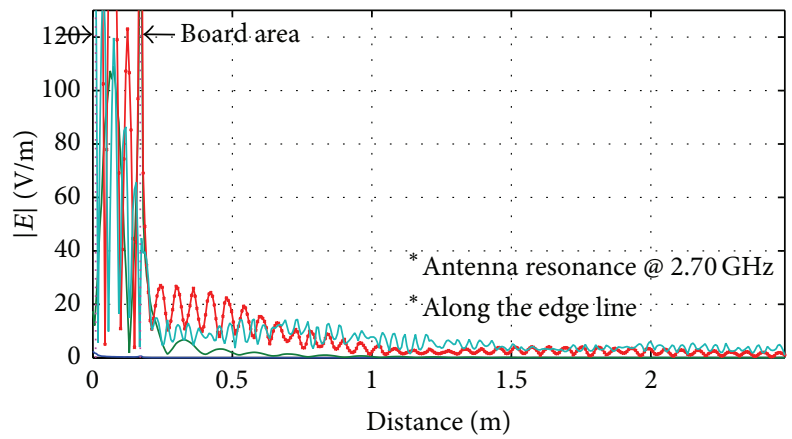

(b)

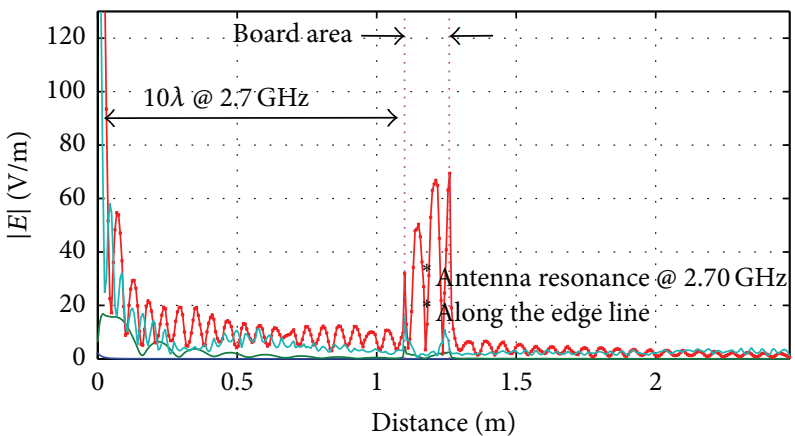

(d)

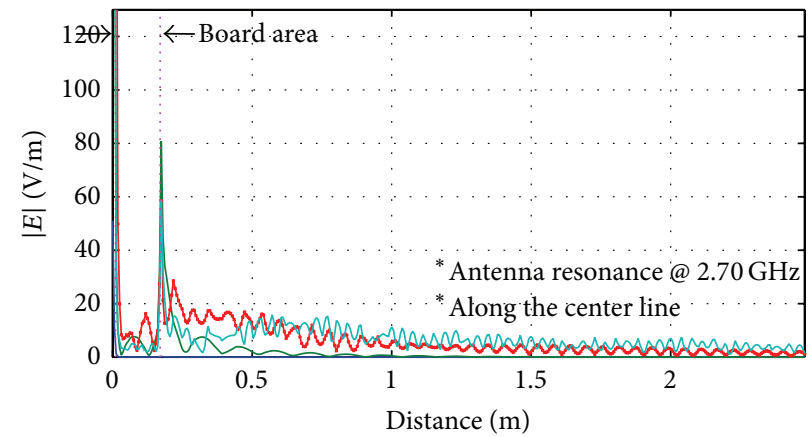

(f)

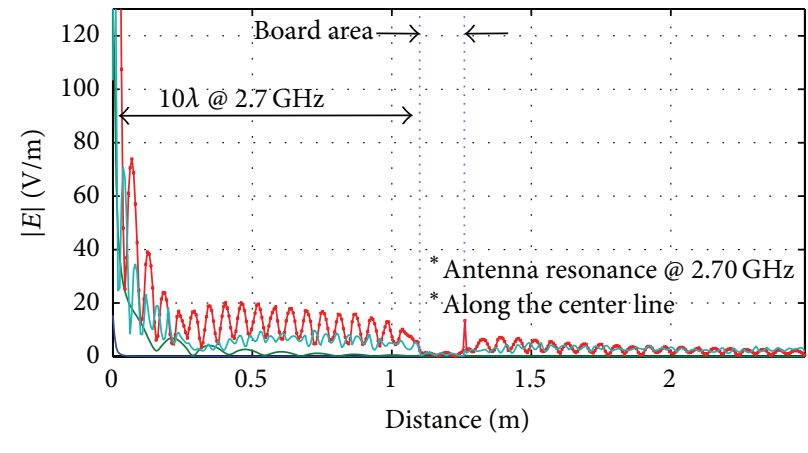

$-0.10 \mathrm{GHz}$, measured $\quad * 2.70 \mathrm{GHz}$, measured
$-1.35 \mathrm{GHz}$, measured $\quad-4.00 \mathrm{GHz}$, measured

(h)

FIgURE 10: (a) Two paths away from antenna: one path is along the edge of the board and the other one is along the center line of the board. $|\mathbf{E}|$-field distributions (e) without board along the path, (b) with board at $10 \mathrm{~mm}$ away from antenna (near field) along the edge of board, (c) with board at $5 \lambda(0.55 \mathrm{~m}$, near field) away from antenna along the edge of board, (d) with board at $10 \lambda$ (1.1 m, far field) away from antenna along the edge of board, (f) with board at $10 \mathrm{~mm}$ away from antenna (near field) along the center line of board, (g) with board $5 \lambda(0.55 \mathrm{~m}$, near field) away from antenna along the center line of board, and (h) with board at $10 \lambda(1.1 \mathrm{~m}$, far field) away from antenna along the center line of board. 


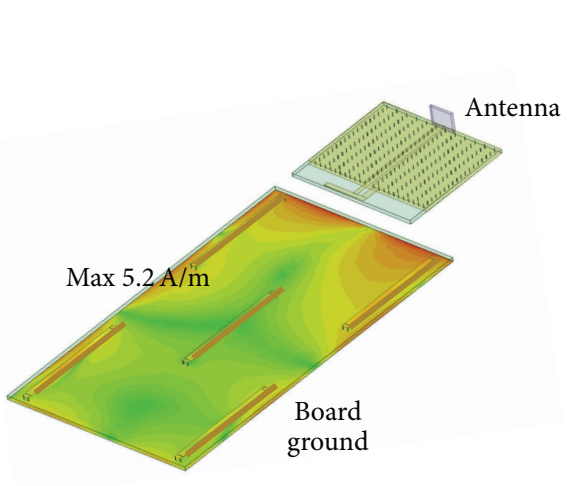

(a)

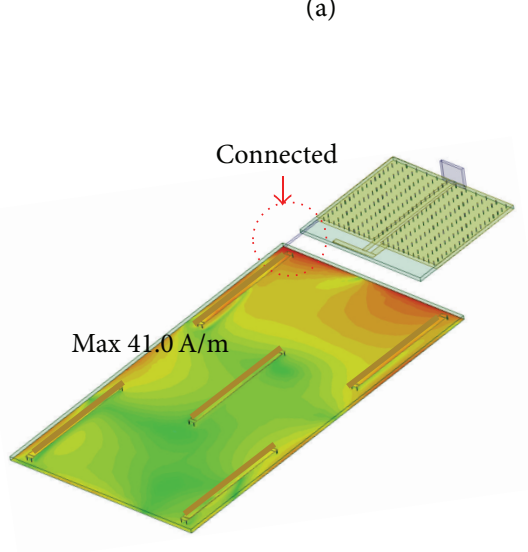

(c)

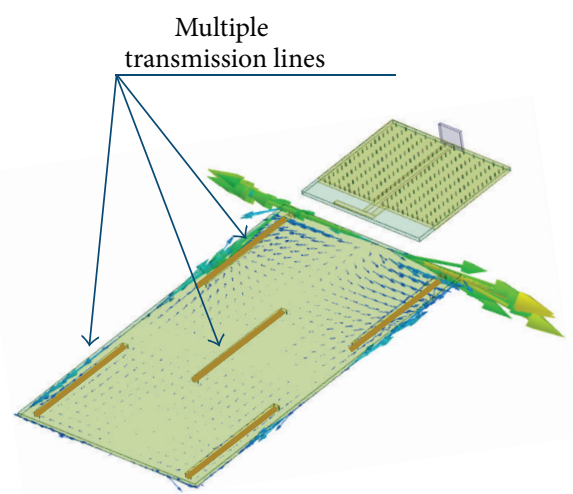

(b)
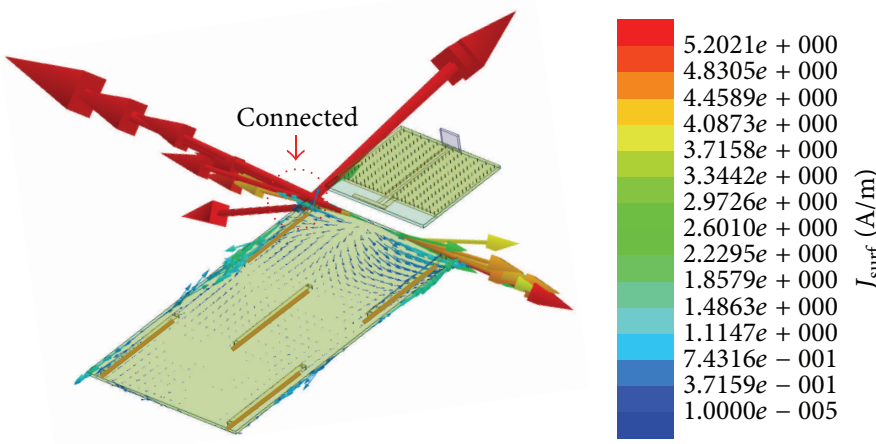

(d)

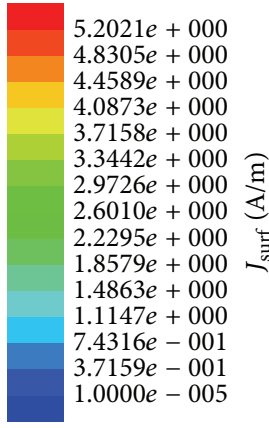

$4.8305 e+000$

$4.4589 e+000$

$4.0873 e+000$

$3.3442 e+000$

列

$1.8579 e+000$ 근

$8863 e+000$

$1.0000 e-005$
$2.6295 e+000$

FIGURE 11: Induced current distribution on the ground with five vertical transmission lines: (a) current distribution with separate ground, (b) current vectors with separate ground, (c) current distribution with common ground, and (d) current vector with common ground.

the edges of the board, while low current density at the Middle of the board, describing the similar current distribution as in Figure 7. From this analysis we again expect high power transfer to the transmission lines near the edges of the board, while there is low power transfer to the transmission lines at the Middle of the board.

The three different transmission lines, shown in Figures 3 and 4 , are the simplified version of transmission lines of a practical PCB, which are of the vertical, horizontal, and bent shapes. Figure 12 shows the measured and simulated power transfer from the antenna to the five microstrip lines on board using the power transfer index. In Figure 12, solid lines are for the measured data, and the dotted lines are for the simulated data. There are five microstrip lines in each board, and we took an average for Upper 1 and Upper 2 and for Lower 1 and Lower 2, respectively. This is because we found that Upper 1 and Upper 2 data show almost the same values and the data of Lower 1 and Lower 2, too. This average also helps make the graphs more recognizable; otherwise they look too complicated to see. Figure 12 shows that the Upper microstrip lines always receive the largest power from the antenna, independent of the line configurations: vertical, horizontal, and bent. Then the Lower transmission lines come and lastly Middle transmission lines, but there are some variations depending on the frequencies. Note that the variation of transferred power is relatively not much for the different line configurations, even though the length of the lines is designed differently as in Figure 3. Also the transferred power to the board with common ground is always larger than the power to the board with separate ground by about $2 \sim 5 \mathrm{~dB}$, and the vertical lines receive the least power from the antenna as a whole. And the transferred power was wide in frequency around the antenna resonance point for all the graphs in Figure 12, and this is again due to the near field characteristics described in the previous section. All these results suggest that the overall characteristics of the transferred power to the multiple microstrip transmission lines are of little difference from the single microstrip line case depicted in Figure 9: more power is transferred to the transmission lines near the edges of the board, especially at the closest edge of the antenna, and is independent of the line configurations and line lengths as a whole. It is good to see that the measured transfer power shows quite a good agreement with simulated results, which validates the suggested methodology in this paper, including the simulation models.

So far, microstrip lines have been used for the analysis of power transfer from antenna, and the last part of this section is devoted to the analysis of the stripline and CPW transmission lines. Figure 13(a) shows the cross-sectional view of three types of transmission lines: microstrip line, stripline, and $\mathrm{CPW}$ transmission lines. All the transmission lines are designed to have $50 \mathrm{Ohm}$ of characteristic impedance with a 


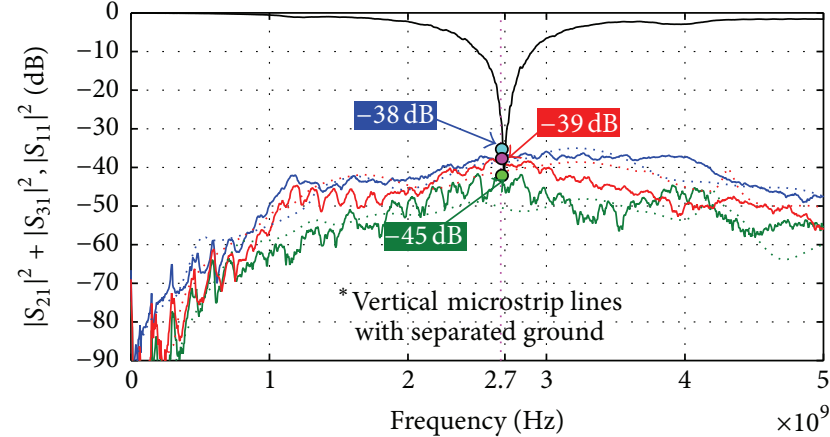

(a)

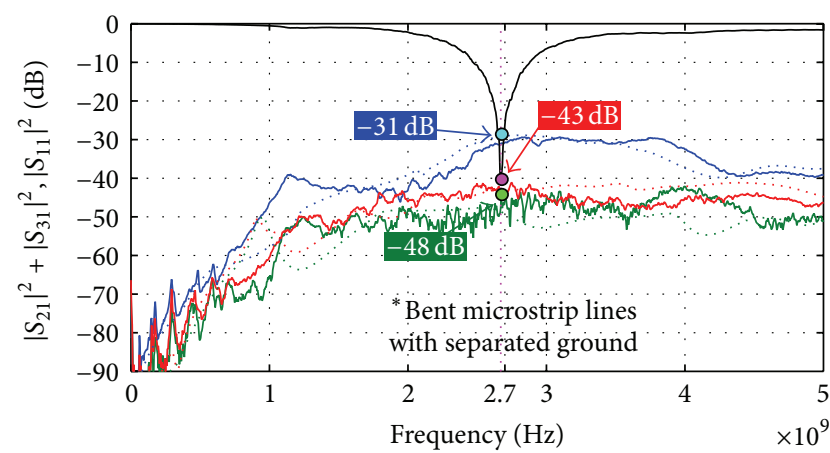

(c)

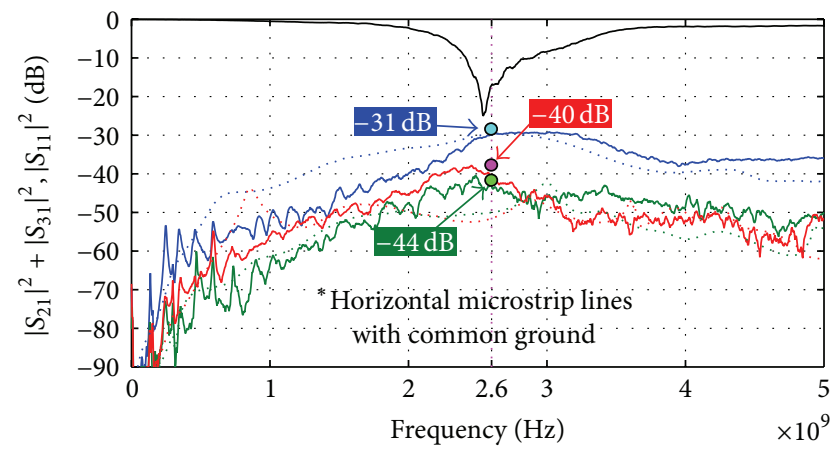

Upper (averaged), simulated Middle, simulated

Lower (averaged), simulated

(e)

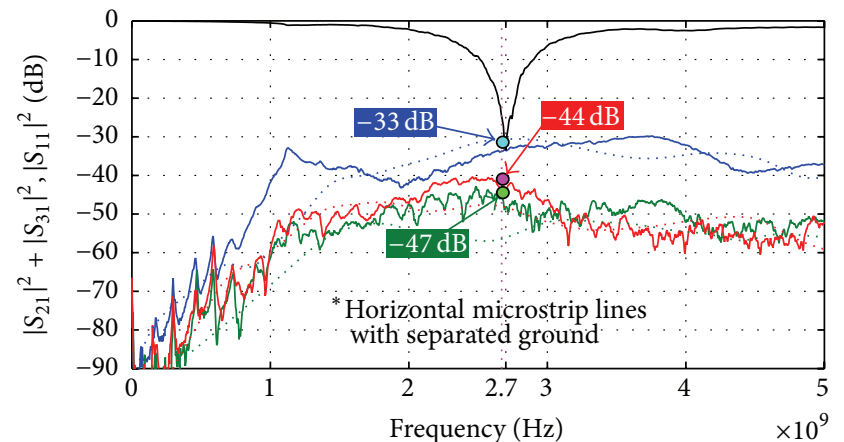

(b)

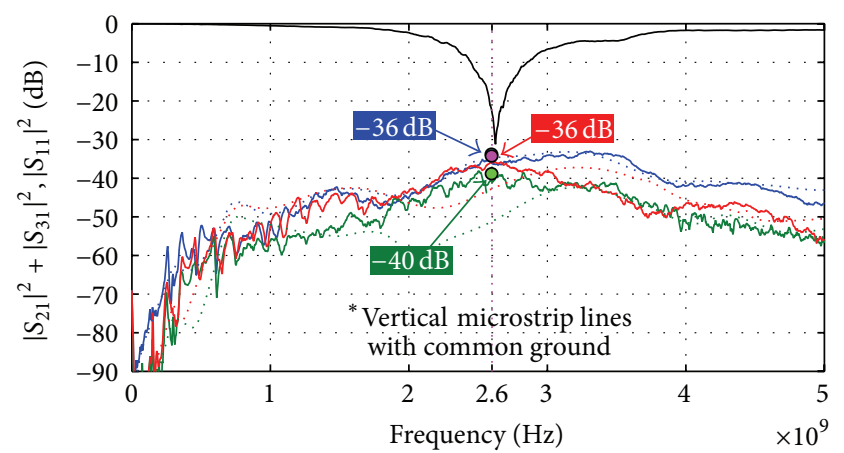

(d)

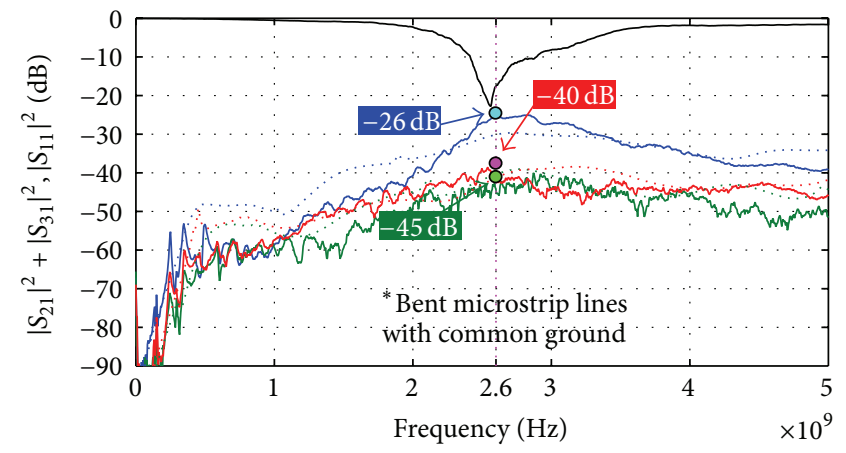

Upper (averaged), simulated Middle, simulated Lower (averaged), simulated

(f)

FIGURE 12: Measured and simulated power transfer from antenna to the multiple (five) microstrip transmission lines with/without ground connection: (a) vertical microstrip lines with separate ground, (b) horizontal microstrip lines with separate ground, (c) bent microstrip lines with separate ground, (d) vertical microstrip lines with common ground, (e) horizontal microstrip lines with common ground, and (f) bent microstrip lines with common ground.

$1.6 \mathrm{~mm}$ thickness, fabricated on the FR4 substrate. Notice that the microstrip line described in (a) of Figure 13 has the same configuration which was used in the previous analysis. Three boards with five vertical transmission lines were designed and fabricated for each type of transmission line, and the power transfer from antenna to multiple transmission lines was measured and is described in (b), (c), and (d) of Figure 13. Since the configuration of transmission lines do not play important role in the power reception from antenna, only vertical lines were fabricated and analyzed with common grounds. Figure 13 shows that the power transfer to the transmission lines at the Middle position is the least and that the power to the Upper and Lower position is quite bigger than the power at the Middle position. There are some variations among the Upper and Lower positions, but stay within several dBs for all the three kinds of transmission lines. Again, we expect high power transfer to the transmission lines near the edges of board and low power transfer at the 

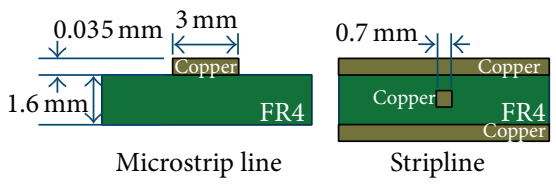

(a)

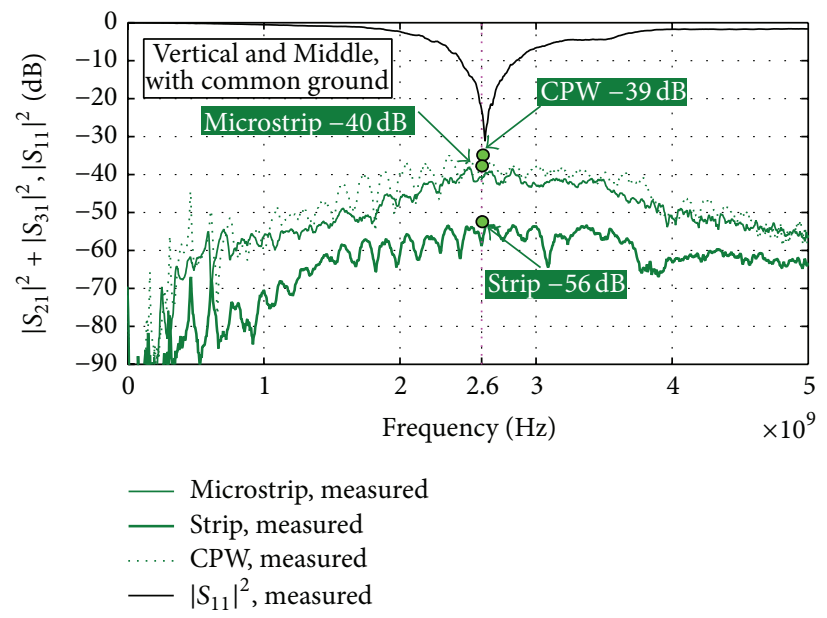

(c)

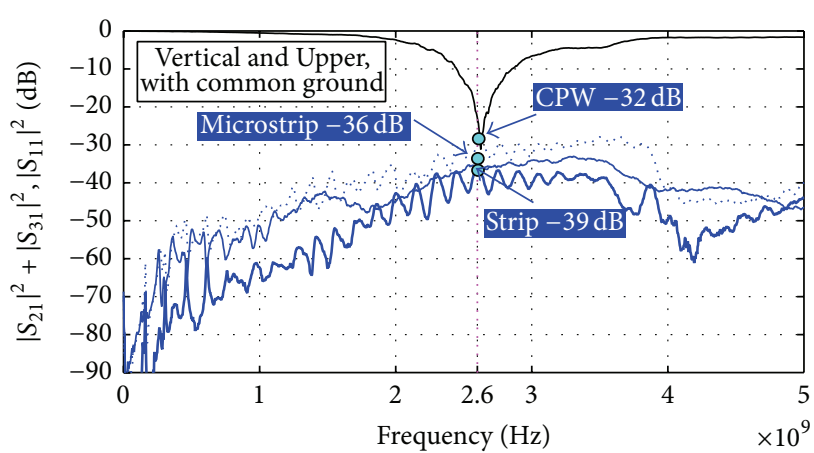

— Microstrip (averaged), measured

— Strip (averaged), measured

….. CPW (averaged), measured

- $\left|S_{11}\right|^{2}$, measured

(b)

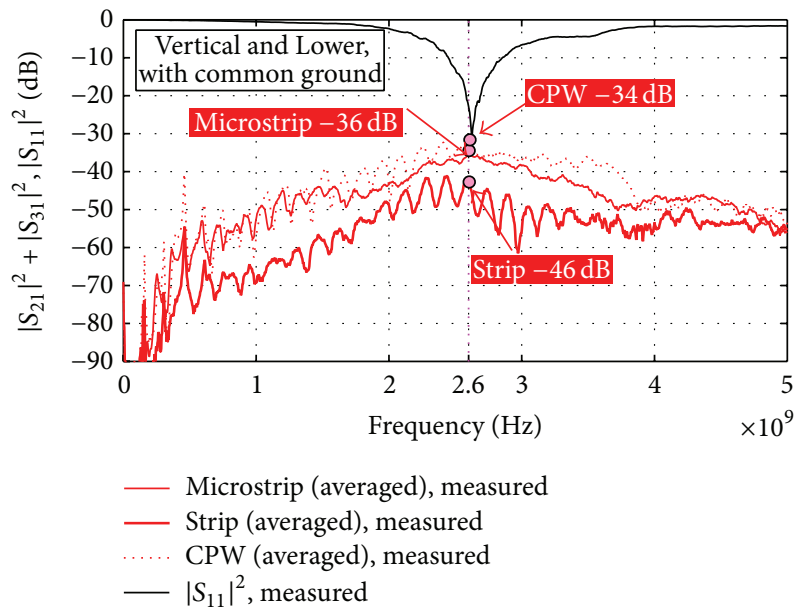

(d)

FIGURE 13: Measured power transfer from antenna to the multiple (five) transmission lines for three different types of transmission lines: microstrip, stripline and CPW. The grounds are connected between the antenna and board, and the five transmission lines are vertically positioned. (a) Cross-sectional view of three types of transmission lines, (b) comparison of transferred power to the transmission lines at Upper position, (c) comparison of transferred power to the transmission lines at Middle position, and (d) comparison of transferred power to the transmission lines at Lower position.

position far off the edges. It is also clear that the transferred power to the stripline is the least compared to the other transmission lines (microstrip line and CPW) by up to more than $10 \mathrm{~dB}$.

It is also confirmed that the power transfer is maximum at the antenna resonance frequency, but the power transfer is not decreasing sharply in the off-resonance frequency range while $S_{11}$ of the antenna characteristics falls sharply, and this is again due to the near field effect. In summary, the power transfer to the stripline and CPW transmission lines is similar to the power transfer to the microstrip lines, and stripline receives the least power from antenna as expected from its structure, and the power transfer is almost the same for microstrip line and CPW within several $\mathrm{dBs}$ in this specific example.

Based on the analysis described above, a design guide to reduce the electromagnetic field interference on transmission lines due to on-board antenna is presented. Firstly, it would be better to use separate grounds between the main system board and antenna to reduce the induced currents on the board. Secondly, transmission lines on the board should be located as far as possible from the edges of the board, and vertical transmission lines would be preferable especially when you use the area close to the antenna as in Figure 14(a). Lastly, when an assembled module (e.g., display module) needs to be installed on the board, it would be better to use the center part of the board to be free from the induced currents along the edges of the main board, which is described in Figure 14(b). In this case, the ground connection point needs to be located as far as possible from the edges of the main board, of course.

\section{Conclusion}

This paper suggests a methodology to analyze the electromagnetic interferences to the transmission lines due to the 


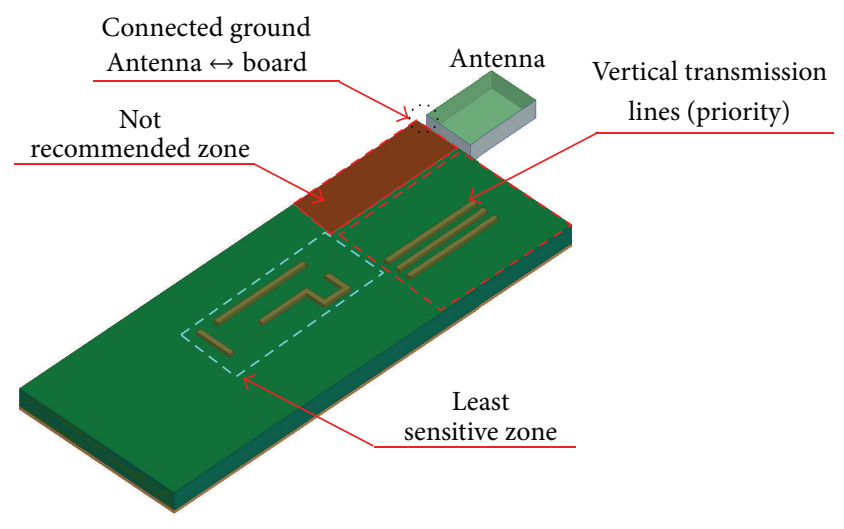

(a)

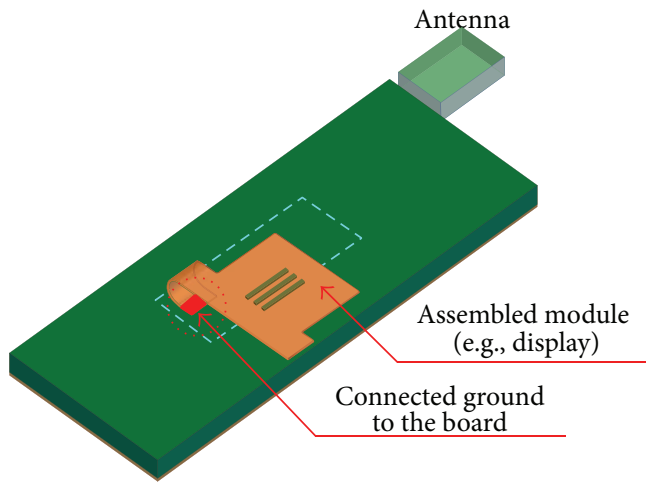

(b)

FIGURE 14: Proposed design guide for (a) transmission lines on the board, (b) the location of assembled module on the board.

antenna on the board. Simplified transmission lines such as vertical, horizontal, and bent lines as well as PIFA antenna were designed and fabricated to measure and calculate the transferred power to the transmission lines from the antenna. Since the transferred power depends on the load conditions, $G_{\text {index }}$ was devised for the comparisons of the transferred power to each transmission line in this paper.

In the analysis, it was found that the transferred power is strongly dependent on the relative position of transmission line from the edges of the board instead of the physical distance from antenna: the nearer the transmission line is located to the edges of the board, the higher the power is transferred from antenna, and the highest transferred power at the closest edge of the board near antenna. And the transferred power to the transmission line of common ground with antenna was always higher than the transmission line of the separate ground, which might suggest that separate ground would be better to reduce the electromagnetic interference to the transmission line on the board. The transferred power was the largest at the resonance frequency of the antenna as expected, but the frequency spectrum of the transferred power was quite wide around the resonance point. This is because the board is located in the near field region of the antenna, where the most of the EM fields are localized, not radiated. This was confirmed by EM field simulation along a path from antenna. Additionally all the measured and simulated powers shown in this paper coincide quite well, which validate the methodology described in this paper. Finally, based on the analysis described in this paper, a design guide to reduce the electromagnetic field interference on transmission lines due to on-board antenna is proposed.

It is hoped that the analysis results and the methodology presented in this paper would be of great help to the circuit designers to reduce the electromagnetic interferences from the antenna on the board.

\section{Conflict of Interests}

The authors declare that there is no conflict of interests regarding the publication of this paper.

\section{Acknowledgment}

This research was supported by Basic Science Research Program through the National Research Foundation of Korea (NRF) funded by the Ministry of Science, ICT and Future Planning (no. NRF-2013R1A1A2009489).

\section{References}

[1] T.-H. Lee, C.-G. Kim, J.-H. Lee, and J.-K. Wee, "Analysis of the EMI and SI effects on the flexible-PCBs for mobile application," in Proceedings of the Electrical Design of Advanced Packaging and Systems Symposium (IEEE EDAPS '08), pp. 97-100, IEEE, Seoul, Republic of South Korea, December 2008.

[2] X. Zhao, J. Tak, and J. Choi, "Worst-case estimate of envelope correlation coefficient for small MIMO mobile antennas below $1 \mathrm{GHz}$," Journal of Electromagnetic Engineering and Science, vol. 15, no. 1, pp. 44-52, 2015.

[3] K. Payandehjoo and R. Abhari, "Compact multi-band PIFAs on a semi-populated mobile handset with tunable isolation," IEEE Transactions on Antennas and Propagation, vol. 61, no. 9, pp. 4814-4819, 2013.

[4] D. Pissoort, M. Mechaik, H. Zeng, C. Shu, C. Jackson, and J. van Hese, "Influence of the interaction between antenna currents and return currents on the coupling between digital interfaces and on-board antennas," in Proceedings of the IEEE International Symposium on Electromagnetic Compatibility (EMC '13), pp. 1-6, Denver, Colo, USA, August 2013.

[5] D. Pissoort, M. Mechaik, H. Zeng et al., "Performance degradation due to coupling between high-speed traces and on-board antennas," in Proceedings of the IEEE International Symposium on Electromagnetic Compatibility (EMC EUROPE '13), pp. 282287, IEEE, Brugge, Belgium, September 2013.

[6] D. Pissoort, H. Fahmy, M. Mechaik et al., "Innovative defense techniques for damping digital to RF crosstalk," in Proceedings of the DesignCon 2013: Where Chipheads Connect, pp. 1-22, Santa Clara, Calif, USA, January 2013.

[7] Y.-S. Wang, J.-C. Lu, and S.-J. Chung, "A miniaturized ground edge current choke-design, measurement, and applications," IEEE Transactions on Antennas and Propagation, vol. 57, no. 5, pp. 1360-1366, 2009. 
[8] J. Kim and H. Kim, "Decoupling method between digital signals on FPCB and mobile handset antenna," ETRI Journal, vol. 33, no. 1, pp. 121-124, 2011.

[9] S. Ryu, J. Jeon, K. Kim et al., Modeling of Noise Power Disturbance from Antenna to Transmission Line System, KIEES, 2014.

[10] K.-L. Wong, W.-Y. Chen, and T.-W. Kang, “On-board printed coupled-fed loop antenna in close proximity to the surrounding ground plane for penta-band WWAN mobile phone," IEEE Transactions on Antennas and Propagation, vol. 59, no. 3, pp. 751-757, 2011.

[11] S. Kim, K. Kwon, and J. Choi, "Design of a miniaturized highisolation diversity antenna for wearable WBAN applications," Journal of Electromagnetic Engineering and Science, vol. 13, no. 1, pp. 29-30, 2013. 

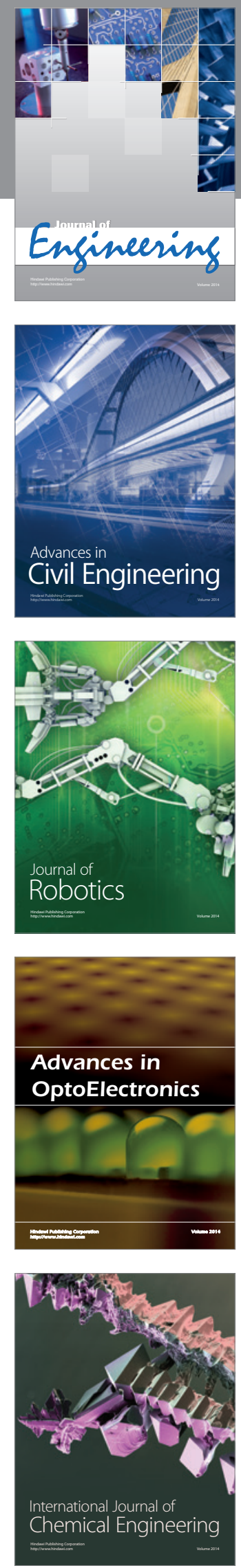

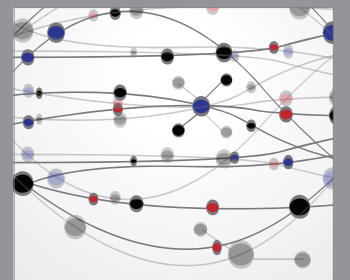

The Scientific World Journal
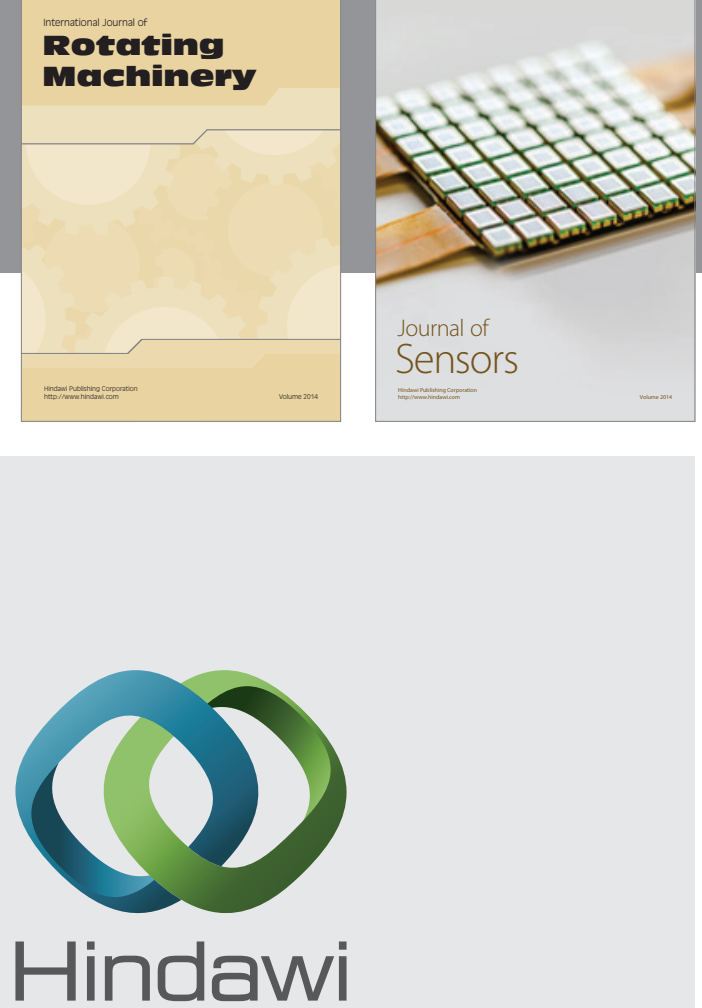

Submit your manuscripts at http://www.hindawi.com
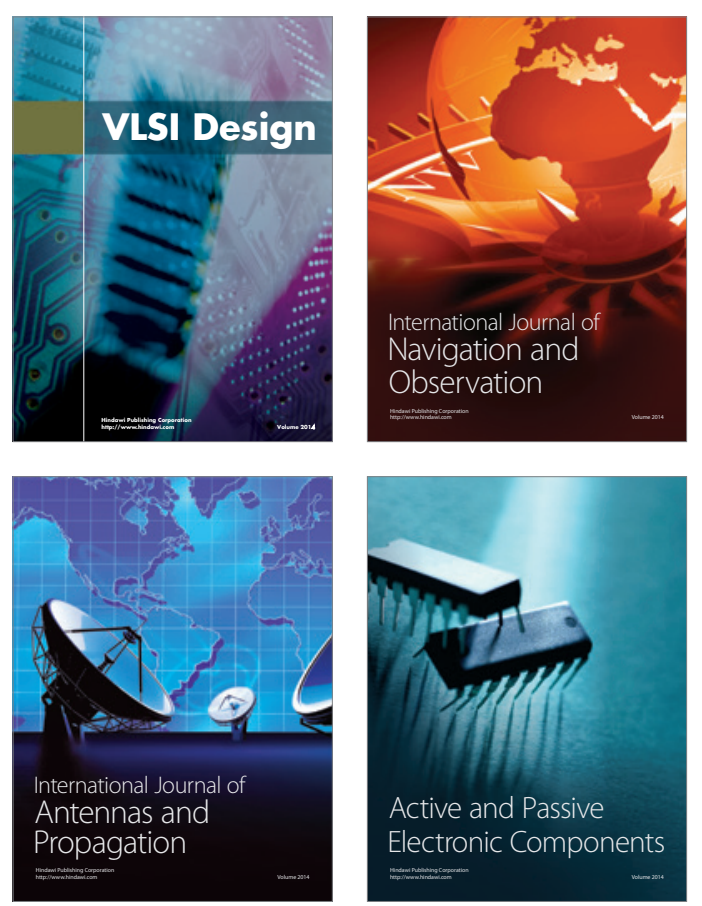
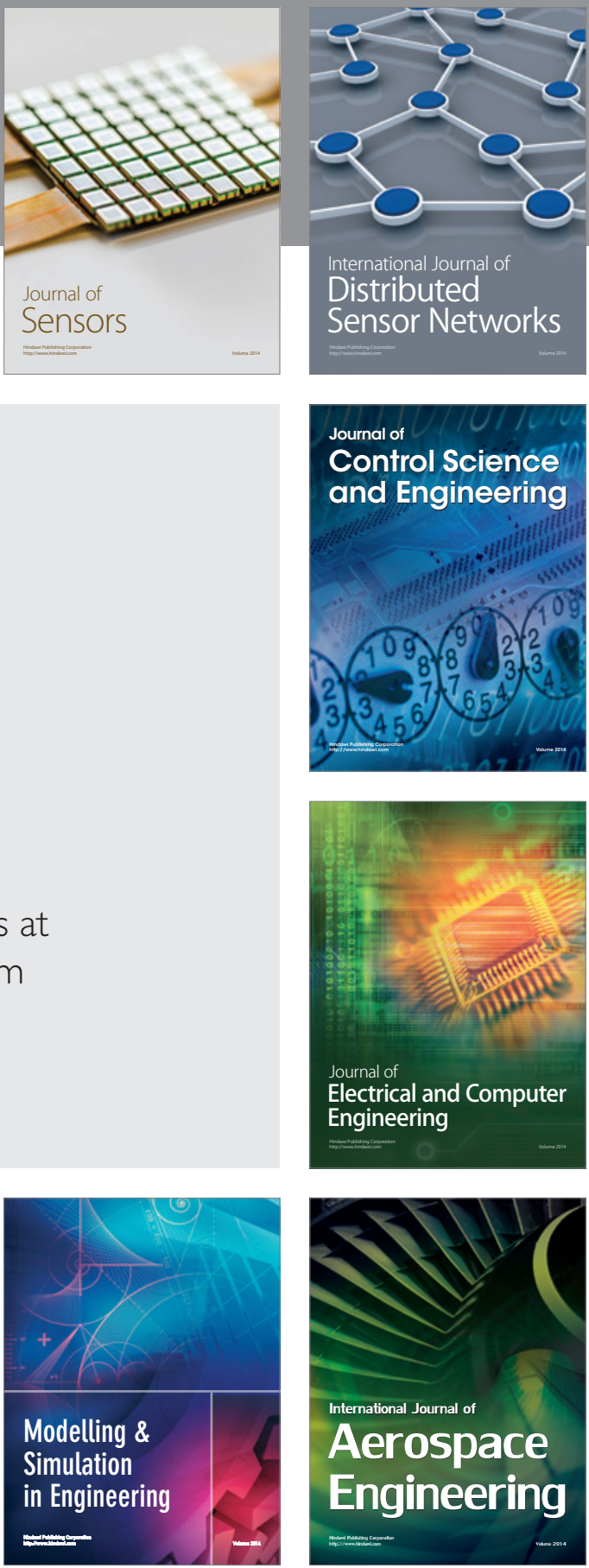

Journal of

Control Science

and Engineering
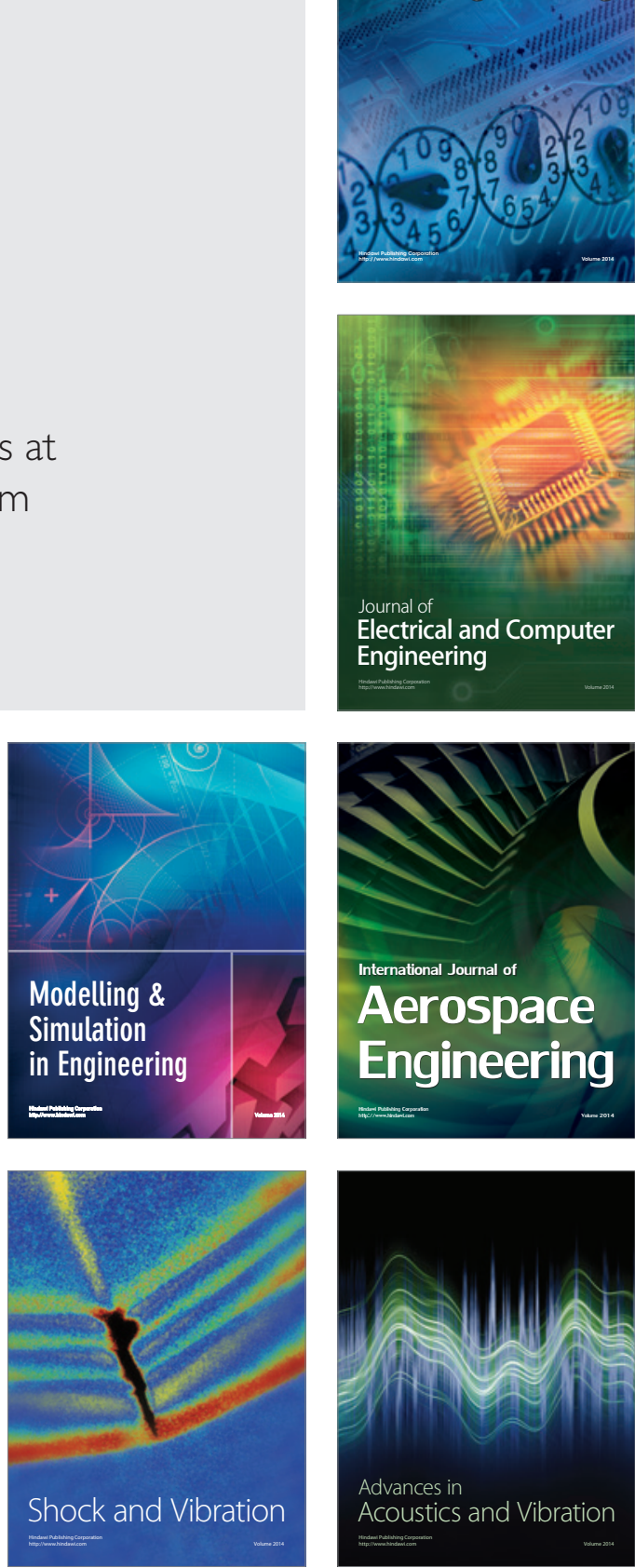